\title{
A CRITICAL REVIEW ON NEW ADVANCEMENTS IN IMPLEMENTATION OF IT IN CONSTRUCTION INDUSTRY: INTEGRATION OF BIM WITH COULD COMPUTING
}

\author{
Vasu Kathi ${ }^{1}$, Srinivas Vasam ${ }^{2}$, K. Jagannadha Rao $^{3}$, M. V. Seshagiri Rao ${ }^{4}$ \\ ${ }^{1}$ Technical Coordinator, NCC International, Hyderabad, India \\ ${ }^{2}$ Research scholar, Department of Civil Engineering, Jawaharlal Nehru Technological University, Hyderabad- \\ College of Engineering, Hyderabad-Kukatpally-500085, India \\ ${ }^{3}$ Department of Civil Engineering, Chaitanya Bharathi Institute of Technology, Gandipet, Hyd -75, India \\ ${ }^{4}$ Department of Civil Engineering, Jawaharlal Nehru Technological University, Hyd.College of Engineering, \\ Hyderabad-Kukatpally-500085, India
}

\begin{abstract}
Over the past decade the construction industry is slowly marching toward the implementation of Information Technology(IT) in its industry and is very slow in when compared to other industries such as production \& manufacturing industries, nevertheless the argument is that implementation of IT in construction is very hard due to its complex structure of various segments in construction industry, but somehow with the advent of Building Information Modelling(BIM) the paradigm of construction industry has been changes and is like never before has been its application benefits it encroached in the construction industry right from project inception stage to the commissioning \& handover of the project. The application of BIM ha gained a lot of attention across the globe in architectural, engineering and construction (AEC) sector The BIM has become the best technique for architectural, engineering and construction (AEC) industries to decrease the project cost, increase the productivity and even improve the quality, accelerates the progress of the project. Even many companies are implementing BIM into their consortium and even developing the tools of BIM by which they can expand their business by far more effectively and efficiently. This paper is mainly intend to give on how much more this BIM can be effectively implemented by using cloud computing throughout the construction projects right from inception to handover and its benefits, applications and implementation process in detail in this paper.
\end{abstract}

Keywords: Constriction Industry, IT, Building Information Modelling (BIM), Cloud Computing, SOA architecture, AEC sector, procurement.

\section{INTRODUCTION}

This AEC (Architectural, Engineering and Construction) sector is the most important one for the growth of the world's economy, in all countries the standards of common life were decided on this sector as the outputs of this sector such as buildings, dams, bridges, sewer systems, infrastructure facilities, transport and network systems, urbanisation etc, which support the economic growth of all public and private (Mena and Lopez, 2010). The construction industry is different to other industries, it consists a typical process. It is a combination of various stakeholders. The implementation of IT has taken the construction industry into a new-era where all processes can be completed within time frame and budgeted cost without compromising on quality and making the user completely satisfied. They are widespread in all the activities such as Computer-aided design and drafting, Building visualisation, Design appraisal, Project management, Information storage and retrieval, Cost estimates, Structural analysis, On-site management, Facilities management and others. The implementation of IT can fasten up the process in construction sector, the benefits are not just time and cost savings but also reduction of risks and uncertain in construction process (Sarshar et al., 2000).
This paper shall discuss on how BIM has become such an efficient tool in construction industry end- end process, it key applicable areas and how the interoperability has become vital approach in construction industry. The various BIM platforms those were present in present construction industry. This paper mainly discuss on how this BIM Process is efficient in different aspects in constriction industry and how this Bim can be much more effectively explored in other divisions such as e-Procurement, etc. This paper also highlights about cloud computing and Service Oriented Architecture, its process and how these constitute for better enhancement of BIM into other divisions effectively.

\section{BIM (BUILDING INFORMATION}

MODELING)

In the recent years the most common buzz word used in the construction industry worldwide is BIM (Building Information Modelling). It has become popular in each and every phase of construction. BIM has gained the attention of many organizations involved in architectural, engineering and construction (AEC) sector and even many companies are implementing BIM into their consortium and even developing the tools of BIM. 
Autodesk defines BIM as 'The creation and use of coordinated, internally consistent, computable information about a building project in design and construction'. Simply to say BIM is a process which considers both graphical and non-graphical aspects of the whole building lifecycle to create a single report of construction documents, designs, schedules and specifications.

BIM makes use of most advanced and upcoming technologies, software's in the industry to build a virtual model of building effectively so that architects and engineers, contractors can access at anytime by making information available to everyone involved, it coordinates many phases of design and construction(Zigo, 2005). BIM makes to take decision based on all the information available which in turns makes the project profitable and improves quality.

\subsection{BIM Technologies}

Building Information Modelling is one product which covers all the fields of construction industry. BIM supplies the continuous availability of project design, cost information, schedules in high quality, reliable, integrated and fully coordinated. It offers a great increased speed of delivery, better coordination, decreased costs, good quality and high productivity.

There are three main phases of Building life cycle for which building information modelling offers access to critical information. They are:

-Design phase: In this design phase, it gathers complete data of designs, detailed scheduling and budget information. In this phase it tries to make the necessary changes where $n$ when required by the client.

-Construction phase: During this phase, it deals with all the aspects like quality, cost information and check whether the project is going accordingly as planned.

-Management phase: In this particular phase the performance utilization of each and every aspect has been considered, and even it also takes into account regarding the financial information.

BIM by effective handling of all phases, it makes the information up to dated and makes the access in an integrated digital environment which gives clear vision of project to all the members. BIM being the best suitable approach for building design, construction and management.

\subsection{BIM Process:}

BIM creates a virtual environment for supporting the stimulation of a construction project. By using appropriate software package identification of possible problems can be traced out during construction stage itself and there by necessary adjustments to the project and to implement in reality (Grilo et al, 2009).

The virtual models created in the BIM can be of surface solid models which carry the information such as size, location, shape etc., of a specific object in the project. These surface model in the recent years has been evolved into model intelligence which means the information is carried out by a virtual 3D model i.e. it posses all the information of an object such as its nature, dimensions and location in relation to other object, its parametric information (GRILO, 2010) quantity \& many more parametric information ( GRILO, 2010). Every object in the building will be having all the minute information which makes the buildings on a whole a 'smart model building'.

Thus in a construction process, by designing a building with the use of BIM models different components of a various model can be used by multiple project team members for various purposes i.e. a model can be sub - divided into various parts (sub-model) where each of these are used by project team for multiple purposes at a time and then all the information can be combined timely to achieve results. A sub contractor who is designated to his portion work can create an architectural, structural \& HVAC model individually and then merge all those information into the project by using these smart models (GRILO, 2009) (GRILO, 2010).

Among many researches GRILO \& JARDIN has conducted a brief research on implementing BIM into procurement process. This enhancement of a e-procurement process with BIM means, a building product objects such as doors, windows, etc... which are created in BIM by 3D model extra information related to procurement are to be induced into such models such as order, invoice, RFD by making use of e-procurement.

As in the construction the process differs from one project to other, various standards are to be created for various dimensions so this create an interoperability within the project $\&$ in various phases of industry. In order to create a link between these various dimension on product $\&$ process model. Grilo suggests that the usage of information architecture \& management models such as Service Orient Architecture (SOA) \& Cloud Computing along with the BIM process may somehow reduces the interoperability problem.

\section{SERVICE ORIENTED ARCHITECTURE (SOA)}

In order to achieve a wide interoperability of software applications \& enterprise models. The Object Management Group (OMG) has made use of Model Driven Architect (MDA) (OMG, 2011). This MDA helps to make an open vendor-neutral approach for any business and technological changes in a company. This MDA clearly segregates both businesses \& applications from the technologies used. It creates the platform independent model for function of business and its usage and documents all the information from the technology, thus enabling the interoperability both within \&across the different platform boundaries. This MDA approach can be clearly illustrated in the below figure. 


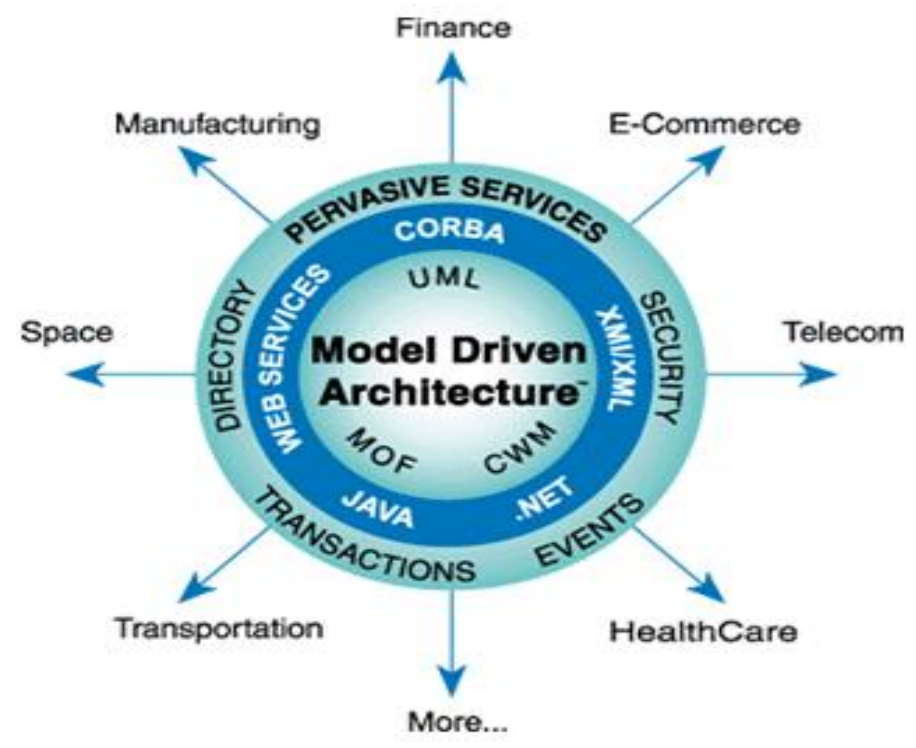

Source:

http://www.omg.org/mda/mda_audio/mda_rollovers/mda_le ft_new2.gif

Object management group (OMG) has defined SOA as "A software architecture which functionally is being grouped across both business processes and packaged as interoperable services". The World Wide Web Consortium (W3C) defines SOA as "A set of components which can be invoked and whose interface descriptions can be published \& discovered" (W3C, 2011).

In a business process, SOA allows various applications to exchanges data with one another in order to make everyone involved in its business process

This SOA offers these services not only in a technological perspective but also provides huge information in order to indentify its functionality, publication, registration. In the construction industry, for faster e- procurement process the research have made an effort to integrate both SOA and MDA so as to create a platform independent model (PIM) which allows automatic transformation between specific target platform \& independent web services, so it can be made automatic \& global. By this approach the architects, contracts, supplies and specialist designer do not need to change the way they work, all they need is to access a repository web service that supports their common interaction process. The recent developments in AEC sector have clearly indicated the potential increase in use of IFC's for both product \& process models in BIM.

Many researchers from their findings have addressed that to some extent a better solution for this problem might be the usage of cloud computing which is used in most recent days very effectively in various sectors globally.

\section{CLOUD COMPUTING}

Cloud computing is the descendent of the evolution on Information Technology (IT) service and products. It is a process based on virtualized resources. This NIST has defined cloud computing as "The model for enabling ubiquitous, on demand networks. Easy access to a shared pool of configured computing resources such as server, network application which can be rapidly provisioned and related with minimal management effects on service provider initial " (NIST, 2011)".

This cloud model is mainly embedded into three service models and four deployment models. The service models are cloud Software as a Service (SaaS) which is for the use of consumer to run cloud infrastructure where these applications can be accessed by various clients. Here the consumer does not manage any of these services, operating systems and networks by his own but is being managed by the third party. The cloud Platform as a Service (PaaS) is another type of service model which deploys onto the cloud infrastructure as consumer-created by using programming languages and tools which were being provided by the vendor. The other service model is cloud Infrastructure as a Service (IaaS). In this service model the consumer has a chance to process, store, networks and to perform other fundamental computing resources (NIST, 2011).The deployment models of the cloud are private cloud, hybrid cloud, public cloud, community cloud. All these deployments were developed according to the needs and security of the project.

The cloud computing is the sum of service model and a deployment model. This cloud computing can be well addressed as the conglomerate of several computing technologies and concepts, it is simply to say as blend of all the technology used in part such as SOA, virtualization, peer to peer (P2D) computing etc,. It is well evident that use of cloud computing is escalating day to day in almost all sectors globally (Feitlu et.al, 2011). This whole process of cloud computing can be shown in the below figure in detail: 


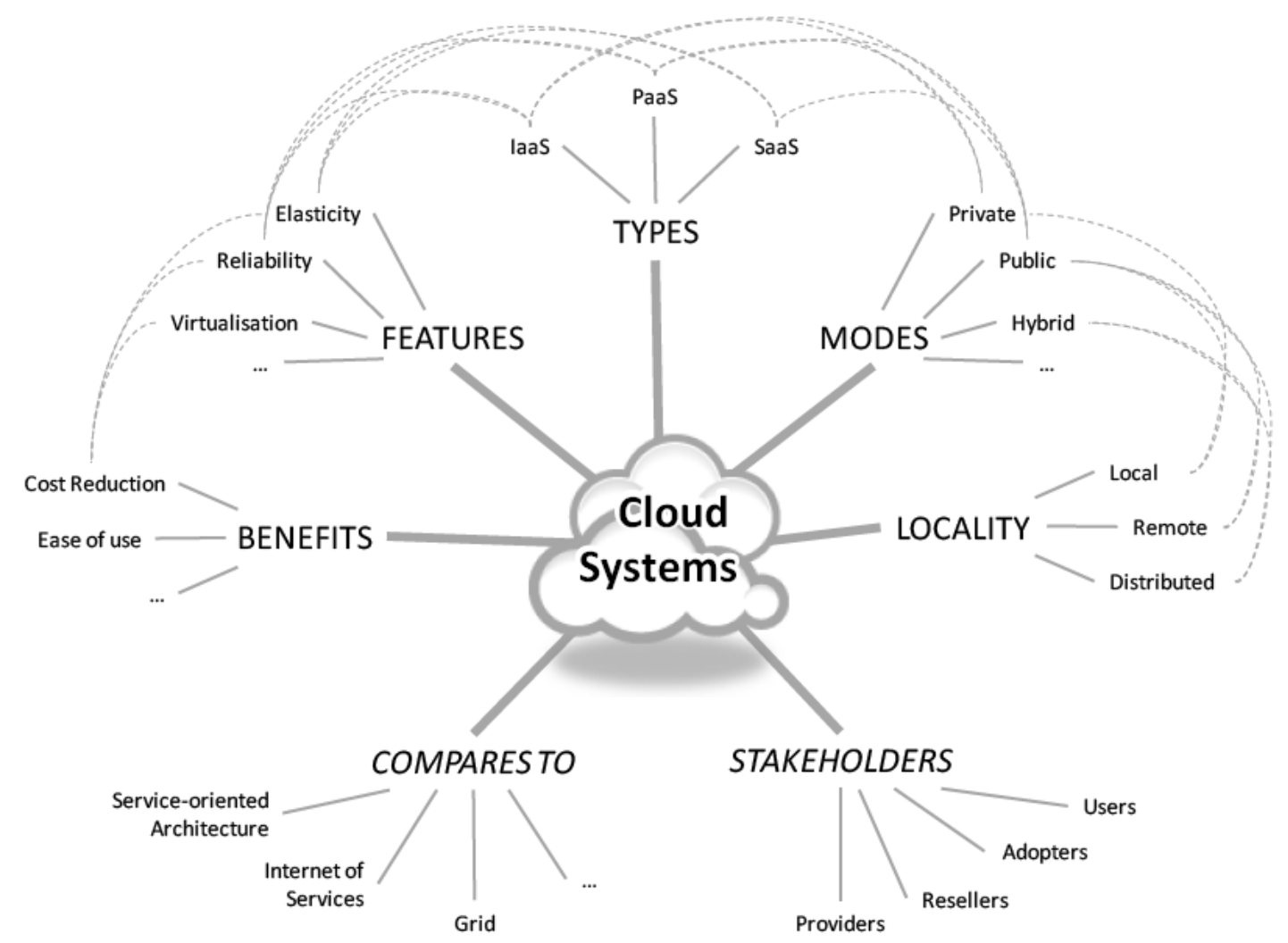

Source: http://www.thakursahib.com/2010/01/business-case-for-cloud-computing/

By this cloud computing, the ICT barriers in all micro- sized and small size firms has been nullified to minimum. This cloud computing offers a wide variety of benefits when compared to traditional service computing, they offers multi-tenancy, shared resources pooling, geo distribution and ubiquitous network access, service oriented modally in systemic manner and dynamic resource provisioning, self organizing, utility based pricing( Zhang et al, 2010).

The cloud computing which is being so far used in various industries has yielded success. In construction industry to offer a more complex service, the online public service provider are making use of cloud computing in eprocurement, real-time processing, online transaction, across the globe ( Bhisikar, 2011). For a proper communication between service providers i.e. to share the application between clouds of different applicants there is a need for standardization of cloud computing, in the year $2009 \mathrm{KDD}($ knowledge discover and data mining) has published a report "open standards and cloud computing" in which it states that " The standards are to be meant for one time when domain achieves some method and then allows the other users to come to single table and have a discussion on common concepts" ( zeller et al, 2009)( Kumar, 2010). By this it made a stand point that there is a desperate need for standardized cloud API but still there is no particular standard approved on a whole. Interpretability which has been a long time problem since IT implementation in construction industry may be somehow being reduced (Grilo, 2011).

\section{BIM +SOA+CLOUD:}

As we have discussed in detail about the various features of BIM and its architectures in a relation to construction sector, a frame work is being developed by combing SOA and MDA and cloud computing involves reducing the interpretability problems in construction sector ( conncalves, 2011).

Many researchers have developed a framework in construction industry; they have tried to build SaaS based framework for construction applications by using webservice technology. For integration of individuals within construction supply chain Cheng in 2009 have developed framework with open source web-services known as SC collaboration. He made use of standards such as SOAP, WSDL, and BPEL for data exchange, process discussion and for composition of these web services by making use of cloud computing technology with SOA frame (Cheng, 2009).

Even though at present there was no implementation of this sort of framework in construction, continuous attempts have been made for successful implementation. Researchers like Grilo and Jardim, conclaves, with the funding from primavera and Microsoft has conducted research on how the SOA4BIM frame work is being used in e procurement process. We shall discuss this framework in detail: 
A generic frame work has been developed by Grilo for the development of AEC sector which is indicated in the below Figure clearly. In these SOA4BIM frame work they have developed a model that designs various models for design, construction and maintenance building processes called a computational Independent Model (CIM). In this CIM level they have adopted CEN/ ISSSBI in relation to high level eprocurement processes. Although this SOA4BIM frame work runs with traditional e procurement, in a work shop conducted on electronic procurement, they insisted to use service trade model. In this framework the e-procurement process in mainly relying on SOA approach, thus SOA when combined with MDA tends to create a Platform Specified Models (PSM) for transformation and service for each type of sectors within construction industry i.e. from CIM, the SOA4BIM considers the technology-neutral modeling of the various type of information with in construction project i.e. cost, time, quality, materials, construction agreement etc,. They have also insisted that BIM approach in carried out by making of standards of IFCs, AP225, and AP228 in PIM layer (Grilo, 2009-2011).

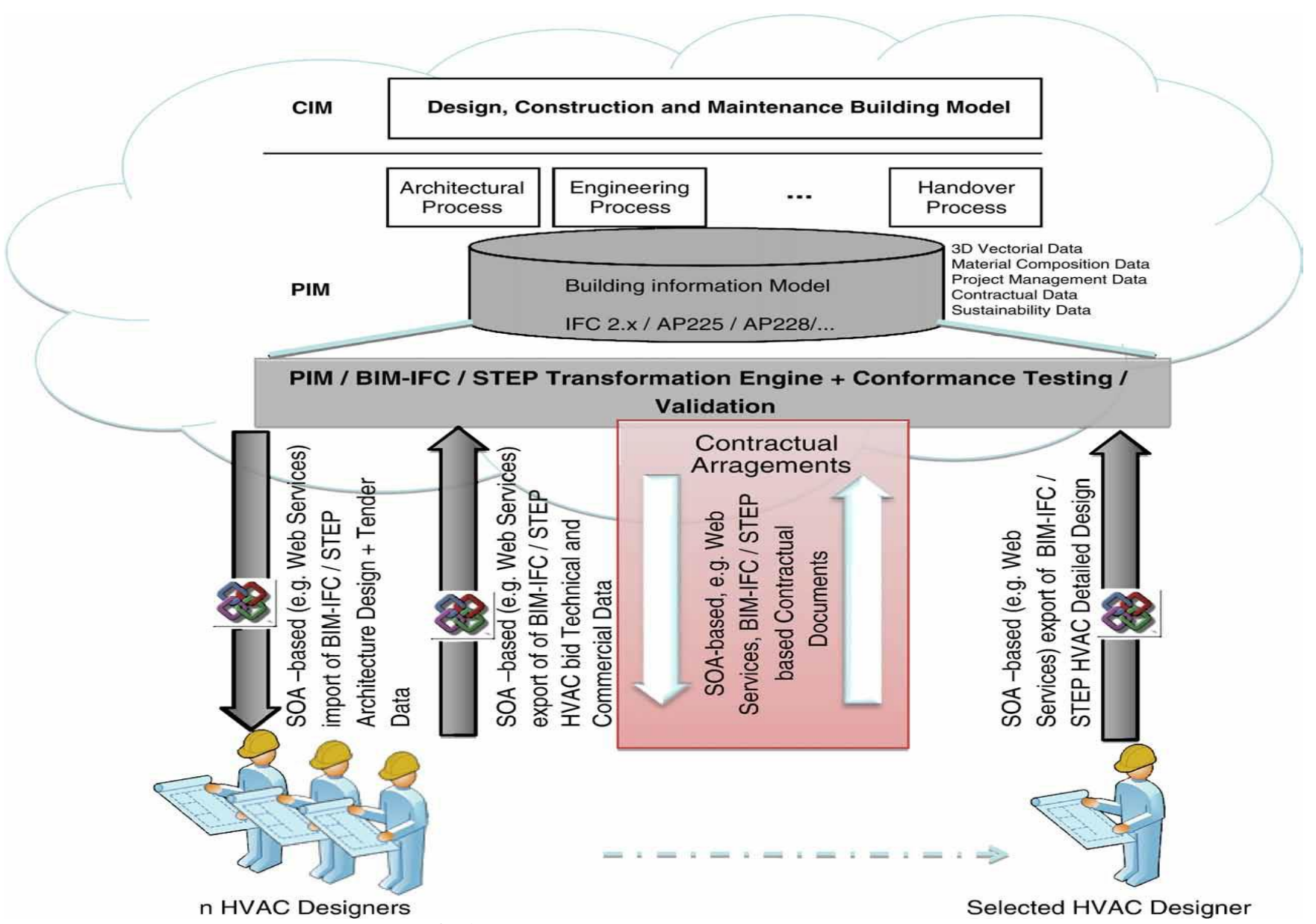

Fig 2: Cloud platform with BIM framework

Source: http:// www.sciencedirect.com/science/article/pii/S0926580509001794

They also explained that by this SOA4BIM framework uses a different framework layer were created in the whole construction project life cycle in all processes of AEC sector, whose in which project life cycle in all process of AEC sector, whose in which for every project PIM- BIM model is to be created. As a testing sequence, they have implemented SOA4BIM framework into a industry R\&D Project known as PLAGE which is being funded by Portuguese government and they tried to analyze and validate this process in which they have created a platform cloud in which they made use BIM- IFC/ STEP technical and constructional data form EPM server to VORTALeGOV for the process of e- tendency, by this approach of implementing BIM in to e-procurement process, they have obtained successful results for design phase of building and engineering projects in relation to the public and private procurement. However they have found some new challenges on which they are making further investigation to nullify them.

\section{CONCLUSION}

From the detail review of this paper it can be understood that BIM has occupied the vital place in construction industry, Building Information Modelling(BIM) has certainly changed the way the building looks BIM is not just a type of software but it is an activity of human which involves the detail process in the construction (Eastman, C., 
2008). BIM will extend its contribution for greater degree and even tries to reduce the documents, errors, waste and productivity.

BIM to be much more efficient, it is to be incorporated with SOA along with Cloud to effectively implement in other divisions such as procurement, logistics etc. On a whole, now many researchers are trying to focus on implementing BIM based framework for managing e- procurement process of a construction industry. By making use of BIM architecture like SOA and with a cloud based BIM server there by, to make clear to construction industry that traditionally barriers in any construction process can be reduced to minimum in whole life cycle of the project. However, the application is not yet commercial as still in the research stage and many effects have been made to bring this type of approach to use in AEC sector fully for more enhancement of IT deployment into construction industry

\section{REFERENCES}

[1] Arvind Bhisikar. (2011) G-Cloud: New Paradigm Shift for Online Public Services. International Journal of Computer Applications. 22 (8), 24-29.

[2] Autodesk. (2010) Revit Architecture. Available: http://usa.autodesk.com/adsk/servlet/pc/index ?id=378 1831\&siteID=123112. Last accessed 26 Dec 2012.

[3] Auto desk. (2007) Implémentation BIM.Available:http://www.autodesk.com/bim.

[4] Bard Hardin (2009) BIM and Construction Management: Proven Tools, Methods, and Workflows. Canada: John Wiley \& sons publishing.

[5] Elaine Knutt (2011) BIM in Cloud. Construction Manager [online] March 2011, p.18 Last accessed 26 Dec 2012.

[6] Fei Hu, Meikang Qiu, Jiayin Li, Travis Grant, Draw Tylor, Seth McCaleb, Lee Butler and Richard Hamner. (2011) A Review on Cloud Computing: Design Challenges in Architecture and Security. Journal of Computing and Information Technology. 19 (1), 25-55.

[7] James P. Lawler and Anthony Joseph. (2011) The Potential Reality of Service-Oriented Architecture (SOA) in a Cloud Computing Strategy.Journal of Information Systems Applied Research. 4 (1), 57-72.

[8] Jim Rubert. (2007). Service Oriented Architecture Standards. Available: http://www.w3.org/2007/01/wos-papers/boeing. Last accessed 28th Jan 2013

[9] L.M.Vaquero, L.Rodero-Merino, J.Caceres and M.A. Lindner. (2009). Break in the clouds: Towards a Cloud Definition. ACM Computer Communication Reviews. 39 (1), 50-55.

[10] Mladen A. Vouk. (2008) Cloud Computing - Issues, Research and Implementations. Journal of Computing and Information Technology. 16 (4), p235-246

[11] Object Management Group (OMG). (2011) $O M G$ Model Driven Architecture. Available: http://www.omg.org/mda/. Last accessed 18th Jan 2013.
[12] Qi Zhang, Lu Cheng and Raouf Boutaba. (2010) Cloud computing: state-of-the-art and research challenges. J Internet Serv Appl. 1 (1), p7-18

[13] Ricardo Jardim-Goncalves \& Antonio Grilo. (2010). SOA4BIM: Putting the building and construction industry in the Single European Information Space. Automation in construction. 19 (4), 388-397.

[14] Ricardo Jardim-Goncalves, Guest editor and António Griloa, Guest editor (2010) Building information modeling and interoperability. Automation in construction. 19 (4), p387.

[15] Shen.W, Hao.Q, Mak.H, Neelamkavil.J, Xie.H,Dickinson. J.K,Thomas. J.R, Pardasani.A \& Xue.H. (2009). Systems integration and collaboration in architecture, engineering, construction and facilities management: a review. Advanced Engineering Informatics. 24 (2), p1-138.

[16] Tim Lohman. (2010) Managing the cloud. Available: http://www.computerworld.com.au/article/341799/ma naging_cloud/\#closeme. Last accessed 12 Dec 2012.

[17] UpendraThakar. (2009) Importance of Building Information Modelling -BIM. Available: http://www.articlesbase.com/small-businessarticles/importance-of-building-informationmodeling-bim-1367487.html. Last accessed 20 June 2010.

[18] Vishal Singh, Ning Gu and Xiangyu Wang. (2011) A theoretical framework of a BIM-based multidisciplinary collaboration platform. Automation in construction. 20 (1), 134-144.

[19] Wilson W.S. (2011). Building Information Modelling and changing construction practices. Automation in construction. 20 (1), 99-100.

[20] Youngsoo Jung and Mihee Joo. (2011). Building Information Modelling (BIM) framework for practical implementation. Automation in construction. 20 (1), 126-133.

[21] Published a Technical Paper on "Practical Approach on Implementation of Building Information Modelling (BIM) in the Construction Industry" at the "National Conference on Advances in Civil Engineering (ACE-2012)" at Vasavi College of Engineering., Hyderabad on 7-8th May, 2012.

[22] Published a Technical Paper on "A Critical Review on Applications of Web-Services in the Construction Industry "at the "National Conference on Advances in Civil Engineering (ACE-2012)" at Vasavi College of Engineering., Hyderabad on 7-8th May, 2012 